\title{
Managing nuclear waste: Options considered
}

Starting in the 1950s, U.S. scientists began to research ways to manage highly radioactive materials accumulating at power plants and other sites nationwide. Long-term surface storage of these materials poses significant potential health, safety, and environmental risks.

\section{A variety of options were considered}

Scientists studied a broad range of options for managing spent nuclear fuel and highlevel radioactive waste. The options included leaving it where it is, disposing of it in various ways, and making it safer through advanced technologies.

International scientific consensus holds that these materials should eventually be disposed of deep underground in what is called a geologic repository. In a recent special report, the National Academy of Sciences summarized the various studies and emphasized that geologic disposal is ultimately necessary.

\section{Leaving it where it is}

Currently, America's spent nuclear fuel and high-level radioactive waste are temporarily stored above ground at 131 locations in 39 states. There are many disadvantages associated with long-term surface storage, even if only for another 100 years.

If left where they are indefinitely, the materials could become a serious hazard to nearby populations and the environment. This could be an even greater concern if global climate change causes the oceans to rise, as many

\section{Scientists looked at many} alternatives

Burying the waste in

- deep geologic repository

- sub-sea beds

- very deep holes

- polar ice sheets

- rock on an island

Sending the waste into space

Injecting the waste in liquid form very deep underground

Transmutation of the waste

scientists believe is happening. Most of the storage sites are near population centers, and because nuclear reactors require abundant water, these sites are also located near rivers, lakes, and seacoasts. If not continuously maintained and safeguarded, this stored material could deteriorate and travel through groundwater and surface water runoff to rivers and streams that people use for domestic and agricultural purposes. Should this occur, 20 major waterways and all U.S. seacoasts could be adversely impacted.

\section{Sub-seabed disposal}

Scientists considered burying radioactive waste under the ocean floor, but there are problems associated with this option. Whether waste buried under the seabed could be recovered, if necessary, is questionable. Developing an 


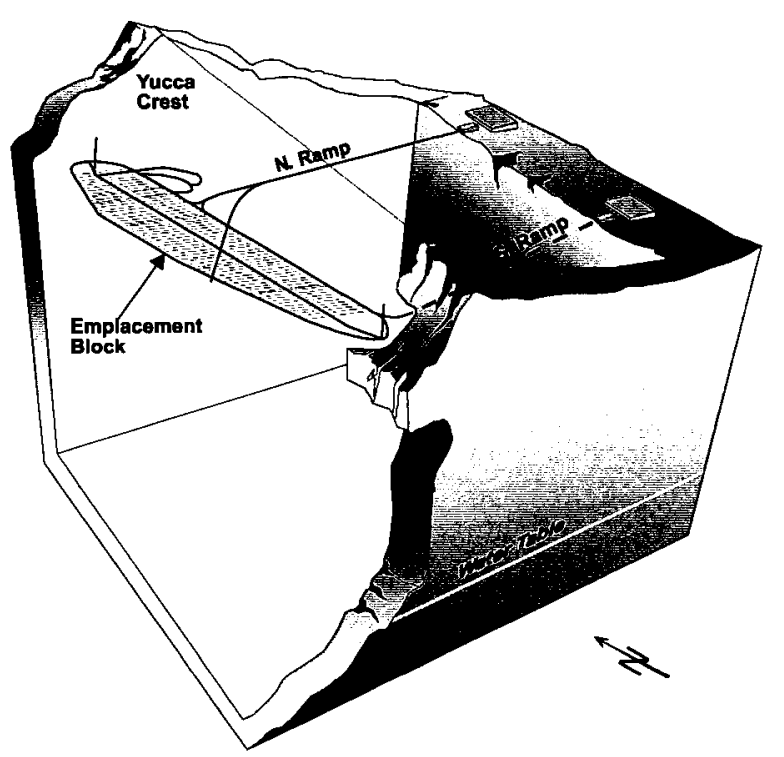

An artist's concept for a deep geologic repository inside Yucca Mountain.

effective international, legal, and administrative structure to develop, regulate, and monitor a subseabed repository would be challenging as well.

Beyond technical and political considerations, the United States signed the London Convention in October 1993. This international agreement, which remains in force until 2018, bans disposing of radioactive materials at sea. After that time, the sub-seabed disposal option can be revisited at 25-year intervals.

\section{Very deep-hole disposal}

Another option scientists investigated was disposal in very deep holes: placing high-level radioactive waste containers as deep as about six miles $(10,000$ meters) underground. At such depths, the radioactivity theoretically could be isolated until it decayed to a safe level.

Very deep-hole disposal was rejected as an option, however. While it would keep radioactive waste below most groundwater, the surrounding rock would have to retain its structure under extreme heat and radiation. Scientists do not know enough about how radioactive waste would behave under the exceptionally high pressures and temperatures of very deep holes.

\section{Space disposal}

The National Aeronautics and Space Administration (NASA) and the DOE also researched several methods of disposal in space. Possibilities included launching waste containers into the sun or putting them on the moon. Space disposal offers the attraction of permanent separation of waste from the human environment. However, the disadvantages of space disposal are great. The possibility of an accident during launch and the potential for radioactive waste to be scattered by such an accident make this an unacceptable option. In addition, space disposal is impractical because of the number of launches that would be required. Establishing international agreements on how such a program would be operated and regulated would also be difficult.

\section{Ice-sheet disposal}

Scientists also considered burying radioactive waste in polar ice. Advantages to this option include the lack of population in polar regions and the stability and thickness (several miles, thousands of meters) of polar ice.

One drawback to this option is the uncertain disposal and/or retrieval processes. Another is the potential effect of future climate changes on the stability and size of polar ice masses. Radioactive wastes could be released into the environment if global climate changes increased polar ice melting. This option also would be extremely expensive due to the remote location and adverse weather. Finally, the Antarctic Treaty of 1959 prohibits disposing of radioactive waste on the Antarctic continent.

\section{Island geologic disposal}

Scientists looked at burying radioactive waste beneath remote islands that lacked valuable resources and were far from large continental landmasses.

One drawback to island geologic disposal concerned the risks associated with ocean transport, especially during bad weather. Also, many islands experience frequent and intense earthquake and volcanic activity. In addition, some islands have geologic structures that allow seawater, as well as fresh water, to penetrate underlying rock. The presence of water could contribute to waste container corrosion, releasing and eventually transporting radioactive particles into the environment.

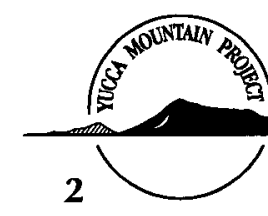


The potential for opposition from nearby countries was an additional consideration.

\section{Deep-well injection disposal}

Scientists studied a disposal option called deep-well injection, which involves pumping pressurized liquid high-level radioactive waste to depths of about 3,500 to 16,000 feet $(1,000$ to 5,000 meters $)$. The waste theoretically would move throughout a porous rock formation protected by a layer of solid (impermeable) rock. Sandstone overlaid by shale is considered a good choice for deep-well injection because of shale's ability to isolate the waste from groundwater and the environment.

One disadvantage to this option was the need for either mechanical or chemical processing of the spent nuclear fuel prior to injection. Another concern was the potential movement of liquid waste outside the porous rock formation. This could increase the chances that the irretrievable waste might escape into the environment.

\section{Reprocessing}

Some nations reprocess their spent nuclear fuel Reprocessing requires a complex set of mechanical and chemical treatments to separate out the uranium from the plutonium, which is produced by the atom-splitting in the reactor. The material can then be reconstituted as fresh fuel pellets to produce more electricity. A byproduct of reprocessing, however, is liquid high-level radioactive waste. Prior to transport or disposal, this new liquid waste must be vitrified, a process by which the waste is combined with sand and other materials and meited together to form a stable glass. This vitrified waste must then be contained and isolated to ensure the protection of public health and safety.

\section{Transmutation}

Transmutation means changing one substance into another. In this case, transmutation refers to changing radioactive elements into less radioactive, or even nonradioactive, substances. The materials must first undergo the complex separation steps involved in reprocessing. Then, using technologies still under development, the materials must be bombarded with neutrons until their atomic structure is changed. If the technologies become operational on a practical scale, they are likely to be very expensive and take a long time to establish and implement.

The DOE supports, and continues to fund, research on transmutation, which could reduce the amount of the most radioactive elements in the commercial spent nuclear fuel. However, as with reprocessing, the high-level radioactive waste produced in the process must itself be contained and isolated to ensure the protection of public health and safety.

\section{Geologic disposal}

In the early 1980s, following environmental impact and other studies, Congress directed the U.S.

Department of Energy (DOE) to pursue an approach called geologic disposal. Geologic disposal involves putting radioactive waste in an underground facility called a repository.

The National Academy of Sciences favors deep geologic disposal. So do many other nations facing similar problems with high-level radioactive waste and spent nuclear fuel.

\section{Geologic disposal becomes national policy}

The geologic disposal concept and the process for finding an appropriate site were spelled out in the Nuclear Waste Policy Act of 1982 and its 1987 amendments. In 1987 Congress directed the DOE to study only Yucca Mountain after it was consistently ranked at or near the top in the technical and scientific characteristics required to serve as a repository. In 2002, Congress passed, and the president signed, a bill designating Yucca Mountain for further development. The DOE still must receive authorization from the Nuclear Regulatory Commission to construct a Yucca Mountain repository and, later, a license to receive and possess spent nuclear fuel and high-level radioactive waste at the repository.

Yucca Mountain is located about 100 miles ( 160 kilometers) northwest of Las Vegas on land controlled by the federal government. If the DOE builds a repository at the site, it would be located in solid rock about 1,000 feet (300 meters) below the surface and, on average, 1,000 feet above the water table. The wastes, all in solid form, would be sealed 
in double-shelled metal containers before being emplaced in one of the repository's tunnels.

A repository at Yucca Mountain would centralize the disposal of high-level radioactive waste in a highly secure location, while maintaining the option to retrieve it. With the waste retrievable, we preserve future generations' options to take advantage of alternative technologies, while protecting the health and safety of the public for thousands of years in the future.

${ }^{1}$ Board on Radioactive Waste Management, National Research Council, National Academy of Sciences, Disposition of High-Level Waste and Spent Nuclear Fuel: The Continuing Societal and Technical Challenges. National Academy Press: Washington, D.C. 2001.

U.S. Department of Energy

Office of Civilian Radioactive Waste Management
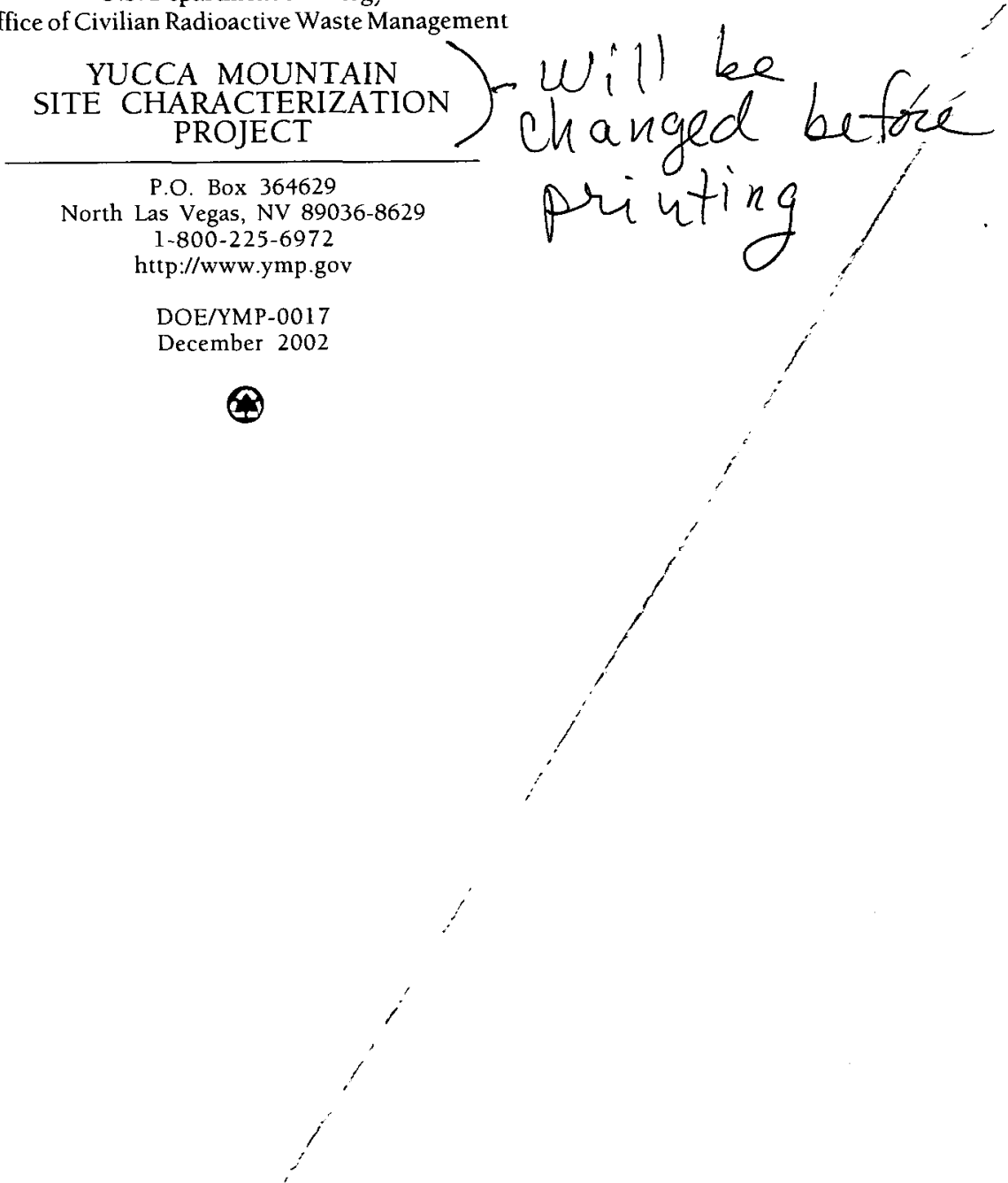